\title{
A multi-agent ecosystem model for studying changes in a tropical estuarine fish assemblage within a marine protected area
}

\author{
Timothée BrochIER $^{1, \text { a }}$, Jean Marc Ecoutin ${ }^{1}$, Luis Tito DE Morais ${ }^{1}$, David M. KAPLAN ${ }^{2}$ \\ and Raymond $\mathrm{LAE}^{1}$ \\ 1 Institut de Recherche pour le Développement (IRD), UMR LEMAR 195/6539 (CNRS/IRD/UBO/Ifremer), BP 1386 Dakar, Senegal \\ 2 Institut de Recherche pour le Développement (IRD), UMR 212 EME (IRD, Ifremer, U. Montpellier II), av. Jean Monnet, \\ BP 171, 34203 Sète Cedex, France
}

Received 14 May 2012; Accepted 21 September 2012

\begin{abstract}
As marine protected areas (MPAs) are increasingly being utilised as a tool for fishery management, their impact on the food web needs to be fully understood. However, little is known about the effect of MPAs on fish assemblages, especially in the presence of different life history and ecological traits. Modelling the observed changes in fish population structures may provide a mechanistic understanding of fish assemblage dynamics. In addition, modelling allows a quantitative estimate of MPA spill-over. To achieve this purpose, we adapted an existing ecosystem model, OSMOSE (Object-oriented simulator of marine biodiversity exploitation), to the specific case of the presence of fish with multiple life histories. The adapted model can manage 4 main categories of life history identified in an estuary MPA: fish that (1) spend their entire life cycle locally, (2) are present only as juveniles, (3) enter the area as juveniles and stay permanently except during reproduction periods, which occur outside the estuary, and (4) are present occasionally and for a short time for foraging purposes. To take into account these specific life-history traits, the OSMOSE code was modified. This modelling approach was developed in the context of the Bamboung Bolong MPA, located in a mangrove area in the Sine-Saloum Delta, Senegal. This was the ideal case to develop our approach as there has been scientific monitoring of the fish population structure inside the MPA before fishery closure, providing a reference state, and continuous monitoring since the closure. Ecologically similar species were pooled by trophic traits into 15 groups that represented $97 \%$ of the total biomass. Lower trophic levels (LTL) were represented by 6 compartments. The biomass of the model species was calibrated to reproduce the reference situation before fishery closure. Model predictions of fish assemblage changes after fishery closure corresponding to the Bamboung MPA creation scenario were compared to field observations; in most cases the model reproduces observed changes in biomass (at least in direction). We suggest the existence of a "sanctuary effect", that was not taken into account in the model, this could explain the observed increase in biomass of top predators not reproduced by the model. Finally, the annual MPA fish spill-over was estimated at 11 tons ( $\sim 33 \%$ of the fish biomass) from the model output, mainly due to diffusive effects.
\end{abstract}

Keywords: Marine Protected Area / Ecosystem model / Tropical estuarine fish assemblage / Life history / Trophic level / Spill-over / West Africa

\section{Introduction}

As a response to the chronic overexploitation of the oceans that threatens marine biodiversity and food security on a global scale (Pauly et al. 2002), marine protected areas (MPAs) are increasingly being used as a tool for fishery management (Roberts et al. 2005). Though MPAs are primarily considered a conservation tool, with eventual economic interest based on tourist activity, there is evidence that MPAs can also be used as a fisheries management tool, as benefits for local fisheries have been observed (Russ et al. 2004; McClanahan et al. 2006), although these benefits depend on a number of factors

\footnotetext{
${ }^{a}$ Corresponding author: timothee.brochier@gmail.com
}

(White et al. 2010). It has been shown that the spill-over of an MPA, i.e., the number of fish "exported" from the MPA that become available for fishing, is related to a number of parameters including pre- and post-reserve human exploitation level, MPA size, shape, age, fish life history and fish ecological traits (Claudet et al. 2008, 2010; White et al. 2010). This has motivated considerable research toward the development of scientific tools that aid in decision making for MPA design (Pelletier et al. 2008; Kaplan et al. 2010). To achieve this purpose, we need to fully understand the impact of MPAs on the food web. However, little is known about the effect of MPAs on fish assemblages, especially in the presence of different life history and ecological traits. Trophic interactions and species 
migrations have been demonstrated to determine the impact of MPAs on species but are not sufficiently taken into account in MPA studies (Claudet et al. 2010; Grüss et al. 2011). This is a direct consequence of the use of classical methodological approaches, such as MARXAN (Ball et al. 2009) or ECOPATH (Christensen et al. 2005, 2009), which generally examine the system in a static state without considering species interactions or migrations. (ECOPATH does allow for interpretations of changes in energy flow through the trophic net.) However, without accounting for the full complexity of fish life histories, there is no way to properly estimate the spill-over of an MPA. In particular, in estuarine MPAs, most of the fish spend only a part of their life inside the reserve. Therefore, this fact must be taken into account during the construction of trophic net models of MPAs, thereby allowing for better estimation of the actual spill-over, qualitatively (by species) and quantitatively.

The modelling of the observed changes that occur in fish population structure after establishment of a MPA can provide in-depth understanding of the dynamics of the ecosystem. MPAs constitute a natural-sized real-world experiment in evaluating the removal of one of the major influences on a marine ecosystem, anthropogenic pressure. Hence, it is a challenge for ecosystem models to reproduce these changes, which would, in turn, demonstrate the validity of the hypotheses made about the main processes driving the ecosystem dynamics. Such validated models could be used both for diagnostic and predictive purposes

Size-dependant trophic interactions and migration patterns can be taken into account with an individual-based model (IBM) or using a multi-agent approach. Furthermore, the model must be spatially explicit to integrate the effects of the size and the shape of the MPA, as those are determinants of fish population dynamics and spill over of the MPA (White et al. 2010). Shin and Cury (2001a) developed such a model, OSMOSE (Object-oriented simulator of marine biodiversity exploitation), a spatially explicit, size-structured, multi-agent ecosystem model. This model can be used to simulate the effects of MPAs on yields and diversity in a theoretical framework without taking into account the diffusive or migratory characteristics of the resource. Yemane et al. (2009) used a "real configuration" with OSMOSE to study the theoretical impact of creating a large offshore MPA off the coast of South Africa for pelagic and demersal species.

In this paper, we propose to adapt OSMOSE to account for differences in life history. These adaptations would allow OSMOSE to be used to investigate the structural changes of trophic nets and to estimate the spill-over of a small-scale estuarine MPA. Marine species use estuaries in a wide variety of ways, including as a nursery area, as a feeding area for top predators and as year-round habitat for locally spawning species. Thus estuarine MPAs typically include fish with a large diversity of life histories. A configuration of the model for a specific MPA in a West African estuary is presented as an example, but the approach can be applied to any estuarine MPA. There are few MPA models including species interactions (White et al. 2011; Baskett et al. 2007). To our knowledge, this is the first modelling tool developed to reproduce field observations of the fish assemblage before and after the fishery closure. Our work is based on data collected over ten years of observation of the Bamboung Bolong, an inverse estuary in the Sine-Saloum Delta of Senegal. This MPA, located in a mangrove area, was created in 2003 and is well documented, as it has been subject to biological monitoring that began before the fishery closure. The main objective of the present work is to present the adaptations made to OSMOSE so as to accommodate the wide variety of life histories found in estuaries and then to apply the model to the specific Bamboung Bolong case.

\section{Materials and methods}

\subsection{Observations and time series}

Monitoring in the Bamboung Bolong began in 2002, with 3 campaigns conducted per year to capture the 3 principal hydro-climatic seasons. In each campaign, a number of stations were sampled along the Bamboung Bolong over a 5-day period. Abiotic observations included measurements of temperature, salinity and turbidity. Biological sampling was carried out using a purse seine All fish were identified, weighed and sized. We refer to the team reports for a complete description of the protocol and the observations (Simier et al. 2004; Albaret et al. 2004; Ecoutin et al. 2010). Here, we used the data from 2002 to 2009 time series observations, i.e. all of the processed data available at the time of the study. These data were used in two ways: (1) to define the model species and (2) to calibrate and validate the model biomasses and size spectra.

\subsubsection{Groups of species}

Groups of species were defined by trophic and ecological characteristics (Ecoutin et al. 2010). Some species or genera (such as Mojarras, African sea catfish and others) form their own group, as they individually represent significant fractions of the total biomass (Table 1). This led to the definition of fifteen model "species", representing 45 real species out of the 74 species observed in the Bamboung Bolong and more than $97 \%$ of the sampled biomass. Physiological characteristics were defined using von Bertalanffy growth and allometric parameters from a typical species of the group. Mean biomasses and size spectra by model species were computed from the data collected in 2002 for the pre-MPA period and averaged from the data collected from 2003 to 2009 for the MPA period. For species that reproduce locally, sex ratio, relative fecundity and reproductive seasonality need to be provided to the model. As fecundity data were not available in the literature for all species, fecundity was estimated using available data of egg diameter, along with an assumption of a constant gonado-somatic ratio of $4 \%$. For this approximation, eggs were considered neutrally buoyant in sea water with a corresponding density of $1.029 \mathrm{~g} \mathrm{~cm}^{-3}$ Spawning seasonality and sex ratio were directly available from local field data.

\subsection{Ecosystem model}

After a review of the few existing multi-agent ecosystem models (Plagányi 2007), we chose to use OSMOSE 
Table 1. Life history model categories for the represented group species, following their ecophase presence in the Bamboung MPA.

\begin{tabular}{|c|c|c|c|c|c|}
\hline Group of species & Type species & Associate species & $\begin{array}{l}\text { Ecological } \\
\text { category* }\end{array}$ & \begin{tabular}{|c|} 
Trophic \\
category $* * *$
\end{tabular} & Life history category \\
\hline Mojarras & Gerres nigri & $\begin{array}{l}\text { Eucinostomus } \\
\text { melanopterus }\end{array}$ & Es & $\mathrm{p} 1-\mathrm{mc}$ & \multirow[t]{5}{*}{$\begin{array}{c}\text { A } \\
\text { (all cycle in the MPA) } \\
\text { Main parameters: relative fecundity, age } \\
\text { or size for maturation, reproductive } \\
\text { seasonality, larval mortality }\end{array}$} \\
\hline Mullets & Liza falcipinnis, & $\begin{array}{l}\text { Liza dumereli, } \\
\text { Mugil curema, } \\
\text { Mugil bananensis, } \\
\text { Liza grandisquamis, } \\
\text { Mugil cephalus }\end{array}$ & Em-ME & he-de & \\
\hline Tilapines & \begin{tabular}{|l|} 
Sarotherodon \\
melanotheron \\
\end{tabular} & Tilapia guineensis & Es & he-ph & \\
\hline Small predators & Monodactylus sebae & Citharichthys stampflii & Em & p2-ge & \\
\hline Bonga shad & Ethmalosa fimbriata & & Em & he-ph & \\
\hline $\begin{array}{l}\text { Small pelagic } \\
\text { fish }\end{array}$ & $\begin{array}{l}\text { Sardinella } \\
\text { maderensis }\end{array}$ & $\begin{array}{l}\text { Ilisha africana, } \\
\text { Sardinella aurita }\end{array}$ & ME & p1-zo & \multirow[t]{4}{*}{$\begin{array}{c}\text { B } \\
\text { (only juvenile ecophase in the MPA) } \\
\text { Main parameters: minimal and maximal } \\
\text { size of individuals, presence } \\
\text { seasonality, abundance of entering } \\
\text { individuals }\end{array}$} \\
\hline Grunts & Pomadasys jubelini & $\begin{array}{l}\text { Pomadasys perotaei, } \\
\text { Trachinotus teraia, } \\
\text { Pomadasys incisus }\end{array}$ & Em & $\mathrm{p} 1-\mathrm{bt}$ & \\
\hline Ladyfish & Elops lacerta & Elops senegalensis & $\mathrm{ME}$ & p2-pi & \\
\hline $\begin{array}{c}\text { Estuarine } \\
\text { macrophagous }\end{array}$ & $\begin{array}{c}\text { Chloroscombrus } \\
\text { chrysurus }\end{array}$ & $\begin{array}{c}\text { Brachydeuterus auritus, } \\
\text { Drepane africana, } \\
\text { Selene dorsalis } \\
\end{array}$ & ME & $\mathrm{p} 1-\mathrm{mc}$ & \\
\hline Stingrays & $\begin{array}{c}\text { Dasyatis } \\
\text { margaritella }\end{array}$ & Dasyatis margarita & Em & $\mathrm{p} 1-\mathrm{bt}$ & \multirow[t]{4}{*}{$\begin{array}{c}\text { C } \\
\text { (enters the MPA as juveniles and stay } \\
\text { in the MPA) } \\
\text { Main parameters: minimal size of } \\
\text { individuals, age or size for maturation } \\
\text { reproductive seasonality abundance of } \\
\text { entering individuals }\end{array}$} \\
\hline Groupers & Lutjanus goreensis & $\begin{array}{l}\text { Epinephelus aeneus } \\
\text { Lutjanus dentatus }\end{array}$ & Ma & p2-pi & \\
\hline $\begin{array}{l}\text { African sea } \\
\text { catfish }\end{array}$ & Arius latiscutatus & $\begin{array}{c}\text { Arius parkii, } \\
\text { Arius heudelotii }\end{array}$ & $\overline{\mathrm{ME}}$ & p2-ge & \\
\hline $\begin{array}{l}\text { Estuarine } \\
\text { predators }\end{array}$ & $\begin{array}{c}\text { Galeoides } \\
\text { decadactylus }\end{array}$ & \begin{tabular}{|c|} 
Plectorhinchus macrolepis, \\
Pseudolithus senegallus \\
Pseudotolithus elongatus, \\
Pseudotolithus typus
\end{tabular} & ME-Em & p2-ge & \\
\hline $\begin{array}{l}\text { Very large } \\
\text { predators }\end{array}$ & $\begin{array}{l}\text { Carcharhinus } \\
\text { leucas }\end{array}$ & Dolphins & Mo & p2-pi & \multirow[t]{2}{*}{$\begin{array}{c}\text { D } \\
\text { (short stays in the MPA for trophic } \\
\text { purposes) } \\
\text { Main parameters: Minimal and maximal } \\
\text { size of individuals, mean abundance } \\
\text { per school, minimal prey biomass }\end{array}$} \\
\hline Large predators & $\begin{array}{l}\text { Polydactylus } \\
\text { quadrifilis }\end{array}$ & $\begin{array}{c}\text { Sphyraena afra, } \\
\text { Sphyraena guachancho, } \\
\text { Trichiurus lepturus }\end{array}$ & ME & p2-pi & \\
\hline
\end{tabular}

(*) Es: estuarine species; Em : estuarine species from marine origin; ME: marine-estuarine species; Ma: marine species accessory in estuaries; Mo: marine species occasional in estuaries.

(**) he: herbivorous; ph: Phytophagous; de: Detritivorous; p1, p2: predator level 1, 2; mc: microphagous; zo: Zooplanktivorous; bt: Benthophagous; pi: Ichthyophagous; ge: generalist. 


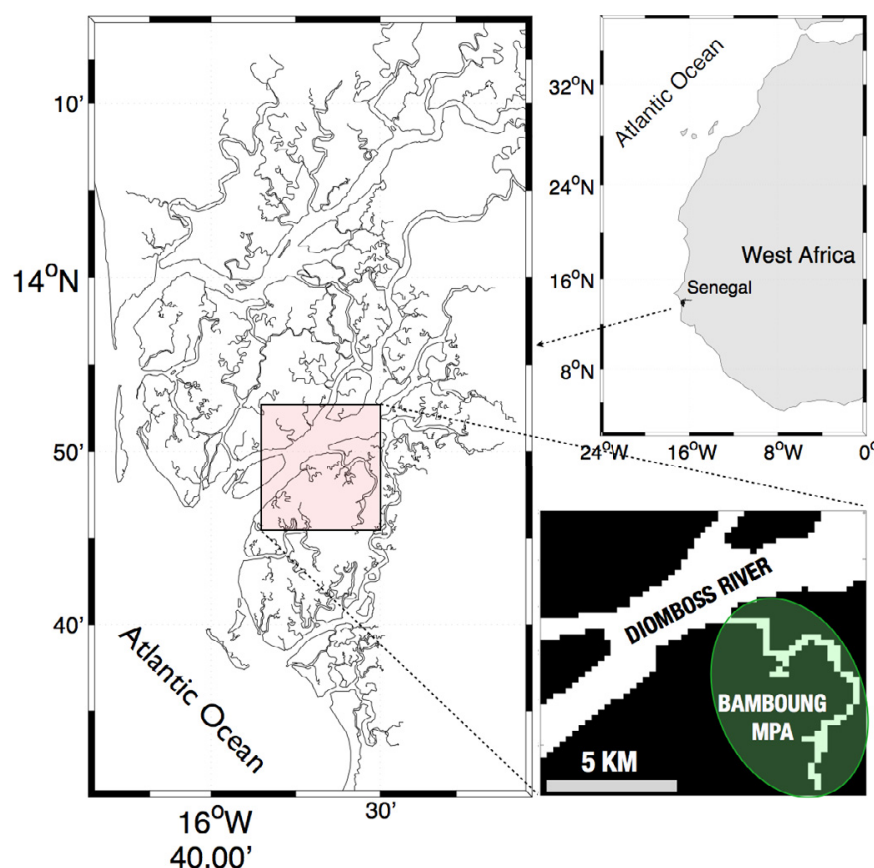

Fig. 1. Map of Senegal and Africa (upper-right). Detailed map of the Sine-Saloum estuary (left). Spatial grid used for the ecosystem model (250 m resolution; bottom-right). Black pixels represent land. The Bamboung Bolong MPA consists of the small tributary river circled in the bottom-right quadrant of the model grid (bottom-right panel).

(Object-oriented simulator of marine biodiversity exploitation), a model of energy flow through an age- and sizestructured ecosystem, as it was the most parsimonious model. Please refer to Shin and Cury (2001b) for a complete description of the basics of this model.

\subsubsection{Environment}

As one of the main objectives of our modelling approach is to study MPA spill-over, we needed to simulate the fish assemblage both inside and outside the MPA to capture the diffusive effect at the border of the MPA. Thus, in our particular case, we chose to model a large part of the surrounding waters, including the area where there was local evidence of fish diffusion from the MPA, i.e., the presence of fishers at the border of the MPA (Kellner et al. 2007). In this paper the environment is considered homogeneous and constant all year round, so that the only spatial heterogeneity is defined by the fishing effort following MPA closure to fishers. The model grid included a total water surface of nearly 5000 ha, the MPA being $10 \%$ of this surface (Fig. 1). The grid resolution was set at $250 \mathrm{~m}$ as a compromise between MPA topology constraints and computing time limitations.

In OSMOSE, the energy input to the ecosystem can be parameterised through an estimate of the lower trophic levels (LTL) biomasses and annual production. The population dynamics of the LTL are not explicitly computed. Mean biomass, yearly production and size spectrum are given as inputs. Six main compartments of the LTL were identified in the Bamboung Bolong, for which biomasses and annual production were estimated either through ECOPATH modelling (Colléter et al. 2012) or from in situ observations.

\subsubsection{Time step}

Ideally, the time step should be set according to the spatial resolution and hypotheses concerning fish movements. To our knowledge, this relationship has not yet been explored in spatial ecosystem models. In the current standard state of OSMOSE, fish move at each time step to adjacent grid cells following a Brownian scheme. Therefore, the time step should be chosen to correspond with the average time actually spent in an area the size of a grid cell. Here, we selected a time step of 1 month, as more precise information on fish migration and movement was not available. Figure 2 presents a schematic flow diagram that depicts the sequence of processes modelled in a time step.

\subsubsection{Number of individuals}

In OSMOSE, "individuals" are actually super-individuals that each represent a fish school containing multiple fish that all pursue the same movement, foraging and predation activities. Hence, the number of individuals is a constant of the model that determines the maximum number of schools for a given species and age class. Not only does this parameter have an impact on the computing time, but it also influences the computed interaction strength between fish. Shin and Cury (2001b) created a sensibility test of the community biomass in an OSMOSE grid for different grid resolutions with a constant number of individuals. They conclude, "When fish are fully accessible (one cell for the grid), some species are depleted by extreme predation pressure and system biomass is low. On the contrary, when fish groups are isolated [...] starvation occurs. System biomass is at a maximum at weak to intermediate strength links. On the other hand, this maximum observed biomass corresponds to a minimum in the CV of community biomass as well as to a higher relative stability of the community compared to species dynamics ([...] when interactions are too strong or too low, they induce a destabilization of the system $(C V / C V e>1)$." In our case, the grid resolution was constrained by the estuary topology, so we performed a sensitivity test of the community biomass with a variable number of individuals. The maximum biomass, and thus system stability, was found using 200 individuals.

\subsubsection{Life history categories}

As OSMOSE is generally used for very large scales that include all of the fish life cycle, we needed to adapt the model for our small estuary to integrate the possibility of partial presence in the model domain four different ecological categories of estuary use were identified for the species considered in our model: (A) species spending their entire life cycle in the estuary, (B) species only present in the estuary during the juvenile stage, (C) species spending their life in the estuary and migrating outside for reproduction and (D) species entering the 


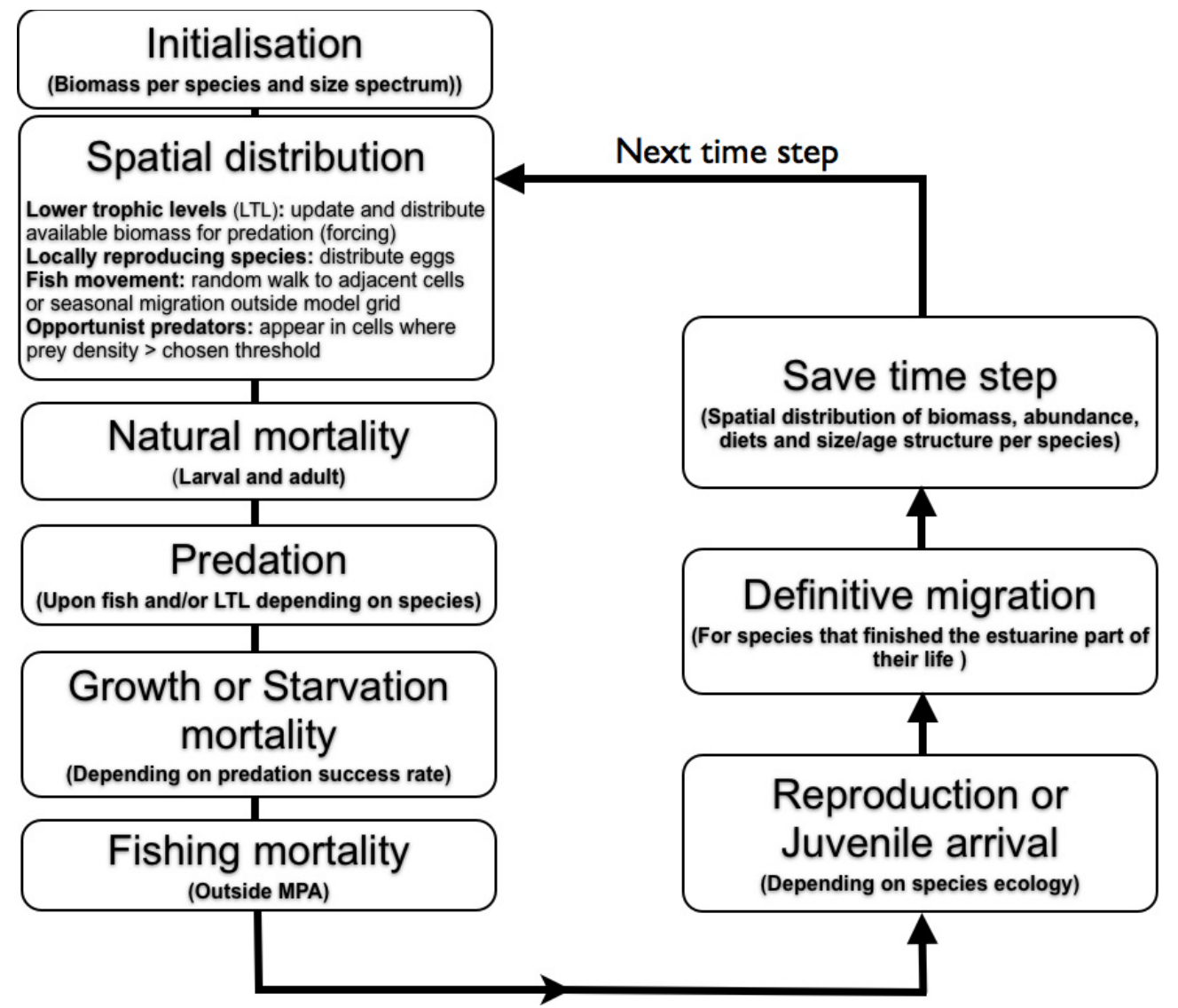

Fig. 2. Schematic flow diagram that depicts the sequence of modelled processes in a time step.

estuary occasionally for foraging purposes (Table 1). Category A species reproduce locally and fall within the original framework of the OSMOSE model. For category B and C species, minimal (and maximal for category B) size observed in the estuary were given, as well as seasonality of juvenile entrance into the estuary For category $\mathrm{C}$ species, mature individuals perform seasonal migrations to reproduce outside the estuary. Estuarine population dynamics for categories $\mathrm{B}$ and $\mathrm{C}$ is initially given by predetermined entrance rates for the arrival of new cohorts, and is then controlled by both predation pressure and food limitation as for category A species. In contrast, for category $\mathrm{D}$, the population dynamics were not explicitly computed by the model. As these top predators have very high mobility in marine systems, their population dynamics are not limited to the MPA or even to surrounding waters. It is assumed that numbers of these species are primarily driven by conditions outside the model domain and that population-wide MPA benefits for these species are negligible (Baskett et al. 2007). Here, we made the hypothesis that their presence in the modelled fish assemblage relies on the abundance of prey available to them, and abundance was assumed to have an attractive effect. As soon as the biomass of potential prey falls below a given threshold in a given location, individuals from category $\mathrm{D}$ which were present in this location simply exit the modelled system.

There was no explicit modelling of the population dynamics for species reproducing outside the modelled system (category B, C and D). The number of new individuals (juveniles, categories $B$ and $C$ ) entering the modelled system per year was constant. These entrance rates were calibrated so that the model reproduced observed biomass values. For category $\mathrm{D}$, the threshold in potential prey biomass required for presence in the model domain was the parameter calibrated (see calibration section). Inter-annual variability in these parameters due to regional scale population dynamics undoubtedly exists, but is not currently accounted for in our model.

\subsubsection{Predation}

Accessibility of potential prey compartments to predatory fish was defined by (1) the size ratio for predation (Table 2) and (2) other restrictions due to known diet limitations for certain fish. Accessibility rules between predator-prey compartments were determined based on expert knowledge and mainly based on qualitative stomach content analysis and other studies in similar environments (Villanueva et al. 2006). The original predation hypothesis in OSMOSE is that each fish can eat a potential prey defined in an interval between two fractions of its own length. However, such a relationship being only based on fish length is inappropriate for a system with a strong diversity of species shape, as some fish are higher or wider than they are long, as is the case in our study area (Fig. 3). As a consequence, the size spectrum of potential prey in this study 
Table 2. Parameters used to determine the size spectra of potential prey. The value 999999 stands for no minimal rate. See Figure 2 for examples of extreme shapes among the Bamboung fish species. Pictures: credits from FAO, FishBase and G. Bertrand.

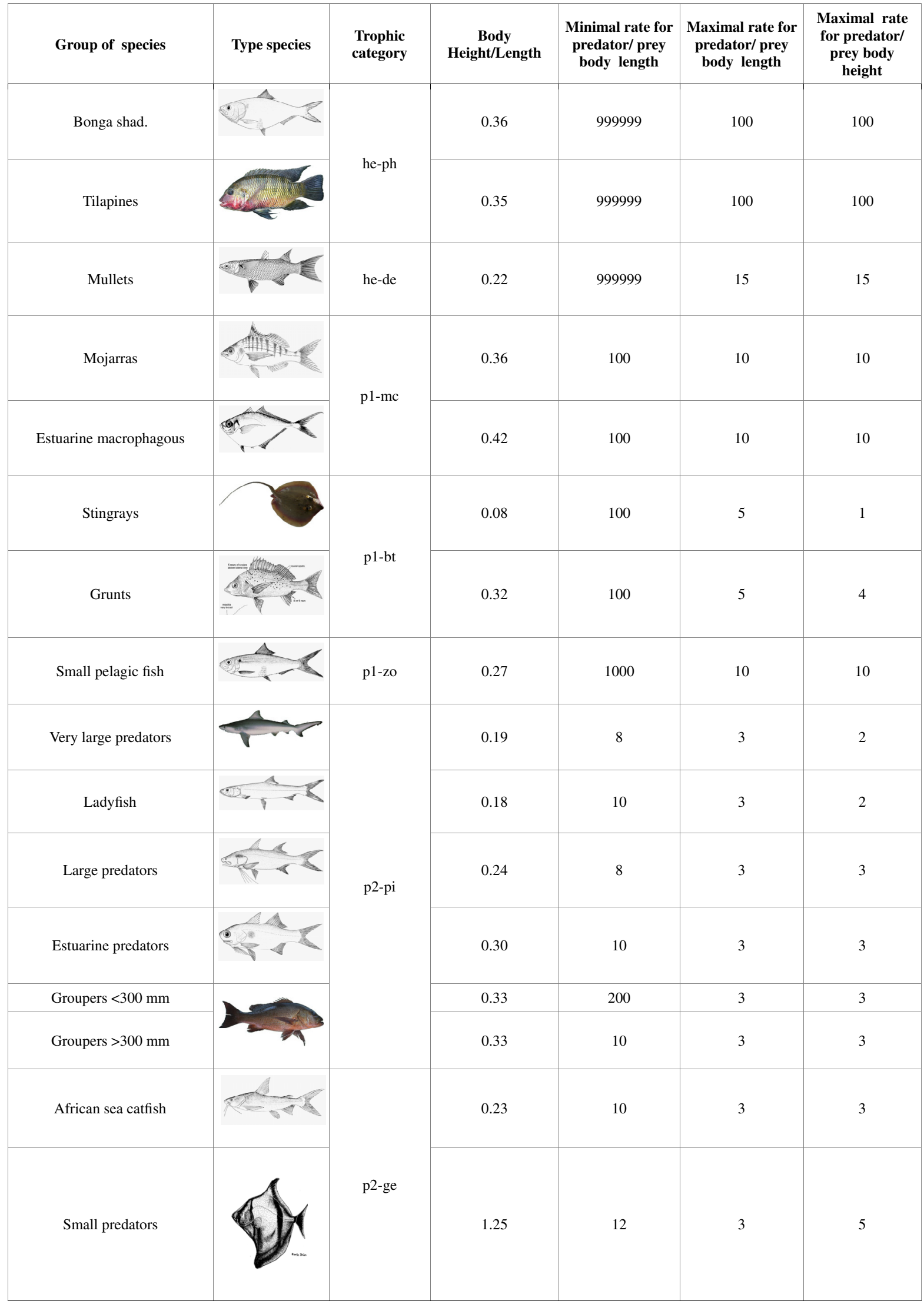


a)

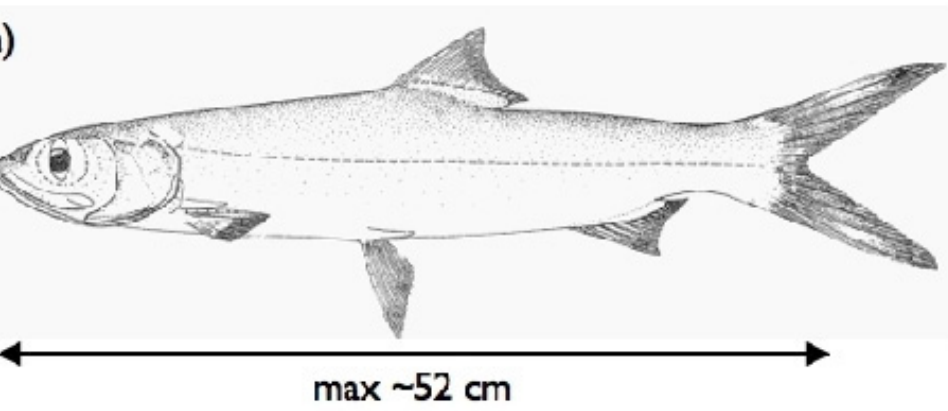

b)

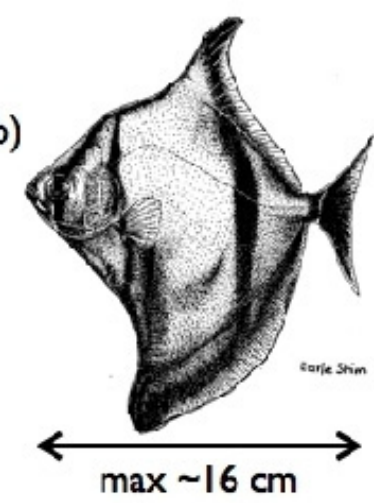

Fig. 3. Example of two extreme fish shapes found in the Bamboung MPA: (a) Elops lacerta, type species for the Ladyfish group; (b) Monodactylus sebae, type species for the "small predators" group. Source: FAO pictures from FishBase (Froese and Pauly 2000).

Table 3. Forced diet parameters. $0=$ no accessibility, $1=$ full accessibility within the size spectra of potential prey size.

\begin{tabular}{lccccccc}
\hline Group of species & $\begin{array}{c}\text { Macro- } \\
\text { benthos }\end{array}$ & $\begin{array}{c}\text { Meio- } \\
\text { benthos }\end{array}$ & $\begin{array}{c}\text { Micro- } \\
\text { benthos }\end{array}$ & Shrimps & $\begin{array}{c}\text { Phyto- } \\
\text { plankton }\end{array}$ & $\begin{array}{c}\text { Zoo- } \\
\text { plankton }\end{array}$ & Fish \\
\hline Bonga shad & 0 & 0 & 0 & 0 & 1 & 1 & 1 \\
Tilapines & 1 & 1 & 1 & 0 & 0.2 & 1 & 0 \\
Mullets & 1 & 1 & 1 & 0 & 1 & 1 & 1 \\
Mojarras & 1 & 1 & 1 & 0 & 1 & 1 & 1 \\
Estuarine macrophagous & 1 & 1 & 1 & 1 & 1 & 1 & 0 \\
Stingrays & 1 & 1 & 1 & 1 & 0 & 0 & 0 \\
Grunts & 1 & 1 & 1 & 1 & 0 & 0 & 1 \\
Small pelagic fish & 0 & 0 & 0 & 0 & 1 & 1 & 1 \\
Very large predators & 0 & 0 & 0 & 0 & 0 & 0 & 1 \\
Ladyfish & 0 & 0 & 0 & 1 & 0 & 0 & 1 \\
Large predators & 0 & 0 & 0 & 0 & 0 & 0 & 1 \\
Estuarine predators & 0 & 0 & 0 & 1 & 0 & 0 & 1 \\
Groupers & 0 & 0 & 0 & 1 & 0 & 0 & 1 \\
African sea catfish & 1 & 1 & 1 & 1 & 1 & 1 & 1 \\
Small predators & 0 & 0 & 0 & 1 & 0 & 0 & 1 \\
\hline
\end{tabular}

also relies on the body height ratio between predator and prey. The relationship between body height and body length was determined from United Nations Food and Agriculture Organization (FAO) pictures of adults taken from FishBase (Froese and Pauly 2000).

Because of natural defences, the accessibility of the African sea catfish group to predation was set at 0 for any potential predator except sharks reported to feed on the African sea catfish. The predation rates for each species, defined as the biomass of prey per unit biomass of predator required to ensure physiological needs of predatory individuals were taken from ECOPATH estimates (Villanueva et al. 2006) and ranged from 5 (very large predators) to 32 (tilapines). Critical predation efficiency, i.e., the minimal rate of biomass ingestion over the needed biomass to allow individual growth, and maximum starvation mortality rate, i.e. the additional mortality that occurs when the rate of biomass ingestion over needed biomass is below the critical predation efficiency, were not defined for each species because no data were available. As these processes are poorly documented in the literature, constant values were used (Shin and Cury 2001b).

\subsubsection{Fishing mortality and MPA}

In the absence of quantitative data on fish landings, fishing mortality prior to MPA implementation was set at $F=0.7$ so as to ensure contrasting results. For medium- to long-lived species, this corresponds to heavy fishing. This mortality was applied to any fish larger than $10 \mathrm{~cm}$, the smallest size landed by local fishers. After the virtual fishing closure in the MPA, the fishing effort was redistributed to the non-protected area such that total effort remained constant over the whole grid (Shin and Cury 2001a).

\subsubsection{Initial conditions}

Initial biomass conditions, as distributed over the entire size spectrum, for each observed species were established before fishing closure. For category D species, the initial biomass was null, but they could enter the system in the first time steps as soon as there was sufficient prey biomass. For category B and $\mathrm{C}$ species, which are not in the area for their whole size spectrum, the initial biomass distribution over the whole size spectrum introduces an error that is rapidly removed after few 
time steps. Finally, initial biomass was an important parameter only for local spawners (category A). The initial biomass affected the relative timing of regular oscillations in certain species (Fig. 1), but long term mean biomass was unaffected by initial conditions.

\subsubsection{Calibration}

For category A species, biomass calibration was achieved by tuning larval natural mortality (predation mortality is explicit in OSMOSE). For category B and $\mathrm{C}$ species, the abundance of juveniles entering the system each year was calibrated. Finally, for category D species, the calibration parameter was the threshold of potential prey biomass needed to attract individuals in each grid cell. This threshold was set as a multiple of the minimal food needed to reach satiety. The model was calibrated based on serial simulations of 15 years with constant fishing effort in space and time (no MPA). The calibration parameters for each species were tuned such that the mean biomass values over the years 5 to 15 were comparable to those observed in the MPA before the fishery closure in the MPA. Each simulation was repeated 3 times, and the mean biomass was obtained from the 3 simulations to compensate for the intrinsic variability of the model. A more rigorous calibration method was also explored using a genetic algorithm to reach the optimal parameters for the observed biomass (Duboz et al. 2010). This method allowed us to rapidly detect errors in the model code or inconsistencies in the configuration, such as non-realistic relative fecundity or errors in allometric relationships. When the algorithm found no solution to fit modelled species biomass to the observed biomass, it revealed an incoherence in the model configuration.

\subsubsection{Simulation of a fishery closure scenario}

Once the model was calibrated to reproduce the annual biomasses observed before the establishment of the MPA, and mean species biomass were stable over a long period (50 years) considering a fishing effort of $F=0.7$ (used for the calibration), a simulation of a fishery closure scenario was performed. A 40-year period was investigated, with the same constant, uniform fishing effort of $F=0.7$ during the first 20 years and fishery closure in the MPA $(F=0)$ from years 21 to 40 , with a uniform redistribution of the fishing effort over the non-protected area. The same simulation was repeated 3 times and ensemble averages were calculated to control for intrinsic variability.

\subsubsection{Output analysis}

The output of the model was extracted spatially to separate the part of biomass corresponding to the MPA from the external area. Biomass temporal series inside the MPA were built by spatially averaging the biomass over the corresponding area to generate a model series comparable to field observations.

Total MPA spill-over estimations included "diffusion spillover" and "migration spill-over", calculated separately for each species group. The former was computed as the difference of the mean biomass in the model area but outside the
MPA after and before the MPA establishment. The migration spill-over included two components integrated over individual years: (1) the sum of the individuals moving out the estuary for reproductive purposes (category C) and (2) the sum of the individuals leaving the estuary once they reach their maximal observed size (category B).

\section{Results}

We principally present results from inside the protected area, before and after fishery closure. However, it is worth mentioning that there was also an area topology effect on the fish assemblage predicted in the model due to the single, spatially-limited point of entrance and exit from the MPA (Fig. 1). Even with a homogeneous fishing effort over the entire model grid, most species' biomass values were significantly higher inside the bolong than in the rest of the area, a result that was robust over the large number of simulations performed for the calibration stage.

\subsection{Calibration}

The tuning parameters obtained from the first manual calibration corresponding to the results presented in this paper are listed in Table 4. Populations achieved stability in multi-year mean biomasses during the 5-year model spin-up time. However, for the local spawners, there were always low frequency variations in biomass, particularly for high fecundity species in such genera as Bonga shad and mullet species Therefore, averaging over years 5-15 of simulations was necessary to achieve a stable calibration.

\subsection{Biomass temporal series}

Biomass temporal series (Fig. 4) present different variability patterns among species. Locally reproducing species (category A), in particular the mullets, Bonga shad and the tilapines, presented strong biomass variability with an irregular period of approximately 5 years, in line with their longevity in the model. These 3 species groups were generally largely the dominant components of biomass. Only the tilapines displayed a clear biomass increase after the fishing ban at year 21. Species present in the MPA only at juvenile stages (category B) had a strong inter-annual variability in biomass. Grunts were the only group in this category that demonstrated a clear response to the fishing ban, with a tripling of biomass from $T=20$ to $T=27$, followed by a biomass decrease until $T=35$ and then a new increase until the end of the simulation. Species from category $\mathrm{C}$ presented strong intra-annual biomass variability due to their seasonal migration outside the MPA for reproduction in the open sea. All species groups from this category displayed an increase in biomass after the fishing ban, although it was less pronounced for Stingrays and rather spectacular for the African sea catfish Lastly, opportunist predators (category D) displayed high intra- and inter-annual variability. The biomass of the very large predators group (sharks and dolphins) increased after the fishing ban, while the large predator group biomass constantly decreased after fishery closure. 

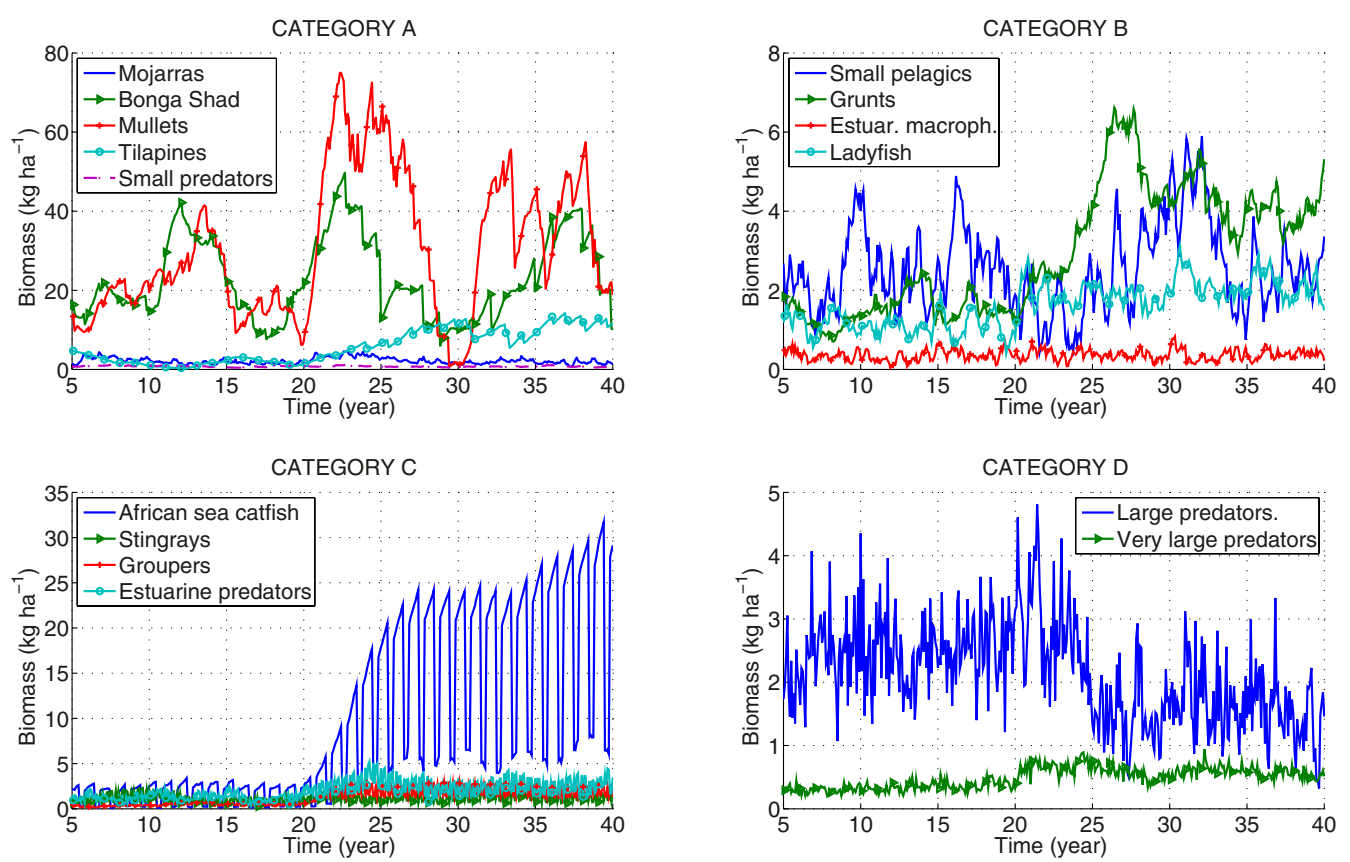

Fig. 4. Model predictions of simulated species biomass time series for life history category A, B, C and D. Fishing closure in the Bamboung MPA began at year 20 in this scenario.

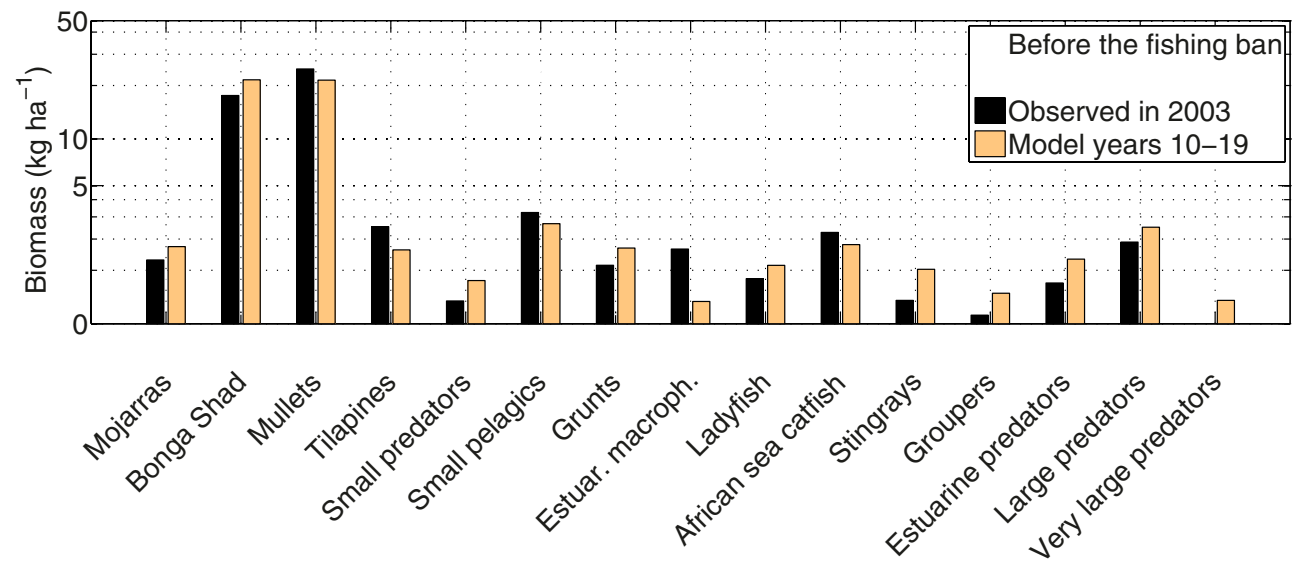

Fig. 5. Comparison between field observed biomass per group of species and model predicted biomass before fishery closure. Note that the vertical scale is logarithmic so as to be able to incorporate the full ensemble of species-groups.

\subsection{Model - data comparison}

Figure 5 presents the initial calibration of the mean biomasses per species. Field data correspond to the mean biomasses observed in 2003, i.e., before the fishing ban, while model biomass outputs were averaged from year 10 to 19 of the simulation. Model biomasses, although not exactly identical to the observed ones, were considered acceptable as they fall within the observational incertitude range and within the inter-annual variability range.

Structural changes that occurred in fish assemblage after fishing closure, observed and predicted by the model, are compared in Figure 6 This figure presents the ratio of biomasses in the MPA and before the fishing ban for each group of species, such that the MPA had a positive (resp. negative) impact on species having a ratio superior (resp. inferior) to 1 Among the
15 groups of species considered, 9 present similar biomass tendencies (increase) in both the field observations and the model, although with different amplitudes. The Bonga shad, mullets, tilapines and estuarine macrophagous biomass decreased in the field observations while it increased in the model. In contrast, the large predator group biomass increased during the field observations, while it slightly decreased in the model prediction.

\subsection{Spill-over estimates}

The model predicted a total annual spill-over increase of approximately 11 tons after fishery closure, corresponding to approximately $22 \%$ of the total biomass estimated by the model in the MPA (approximately 50 tons) and approximately 
Table 4. Calibration parameters values needed to reproduce the initial, pre-MPA situation.

\begin{tabular}{ccr}
\hline Group of species & Calibrating parameter (unit) & $\begin{array}{r}\text { Value found after the } \\
\text { calibration process }\end{array}$ \\
\hline Mojarras & & 7.5 \\
Mullets & Larval mortality $\left(\right.$ year $\left.^{-1}\right)$ & 9.3 \\
Tilapines & 4.5 \\
Small predators & 7.1 \\
Bonga shad & & 8.1 \\
\hline Small pelagic fish & & 3000000 \\
Grunts & 100000 \\
Ladyfish & 45000 \\
Estuarine macrophagous & Number of juveniles entering the MPA per year $\left(N\right.$ year $^{-1}$ ) & 1800000 \\
Stingrays & 500 \\
Groupers & Minimal threshold of total prey biomass & 500 \\
African sea catfish & (multiple of the minimal biomass needed for satiety) & 45000 \\
Estuarine predators & (no dimension) & 175000 \\
\hline Very large predators & & 25 \\
Large predators & & 25 \\
\hline
\end{tabular}

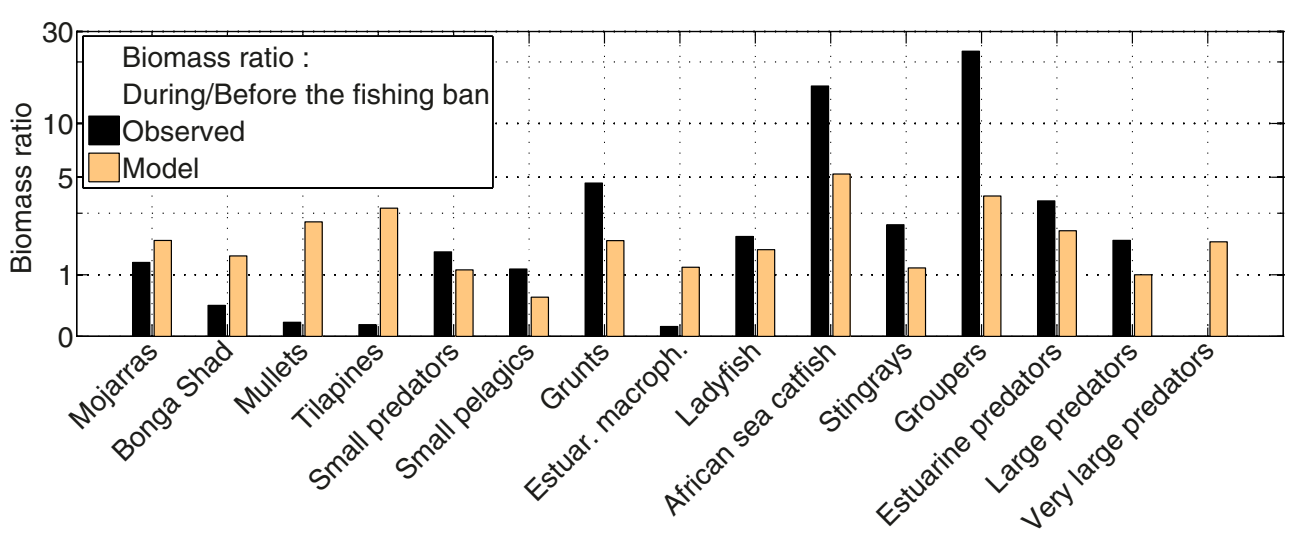

Fig. 6. Comparison of biomass in the MPA after fishery closure between field observed biomass per group of species and model predicted biomass. Note that the vertical scale is logarithmic so as to be able to incorporate the full ensemble of species-groups.

$33 \%$ per cent of the total biomass observed through field samplings (approximately 35 tons). The great majority of the spillover $(75 \%)$ occurred through fish diffusion at the border of the MPA, while long distance migrations were responsible for $25 \%$ of the spill-over (Fig. 7). Most (82\%) of the spill-over involved diffusion of locally reproducing species (category A, Fig. 7). Seasonally migrating species (category C) accounted for $15 \%$, the very large predator group accounted for $3 \%$ and species returning to the sea after spending their juvenile stage in the MPA accounted for less than $1 \%$ of the spill-over. These values were roughly correlated with the proportion of each category in the MPA.

\section{Discussion}

The model properly reproduced the overall observed situation in the Bamboung MPA. The large variability predicted for mullets and Bonga shad is coherent with typical population dynamics of these local, high-fecundity spawners (Denney et al. 2002). Model predictions of the directionality of changes in fish biomass after fishery closure were in agreement with observed field changes for 11 groups of species among the 15 represented by the model. However, there were a number of discrepancies between the model predictions and field observations for the other species. Field observations presented a decrease in biomass for the Bonga shad, mullets and the tilapines species group, a decrease that was not predicted by the model. This is likely related to an increase in the biomass of large predators in field observations, while the model predicted a biomass decrease for this group. We suggest two possible explanations for this discrepancy. First, there may have been an incorrect definition of the diet of large predators that would lead to over-estimation of their predation on estuarine predators and grunts and under-estimation of their predation on Bonga shad, tilapines and mullets, suggested by the analysis of diet per species (not shown). The purely size-based predation applied here does not take into account the different level of accessibility depending on prey habitats (e.g. pelagic or mangrove). The other explanation may be the existence of a "sanctuary effect" that may attract large predators to the MPA, not only to forage, but also in an attempt to avoid the surrounding fishing pressure. Several clues from field observations suggest the existence of this sanctuary effect, as the biomass of 
Spill-over Mechanism

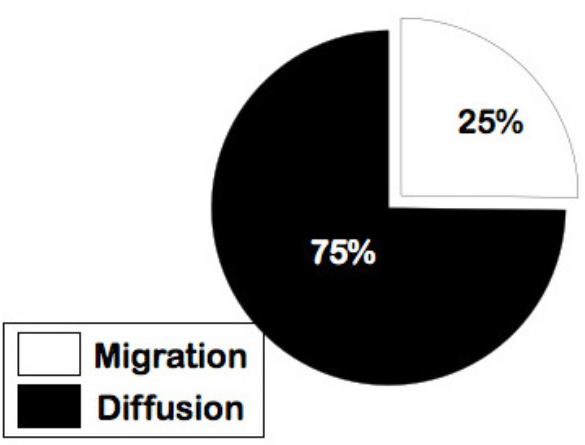

Life history category

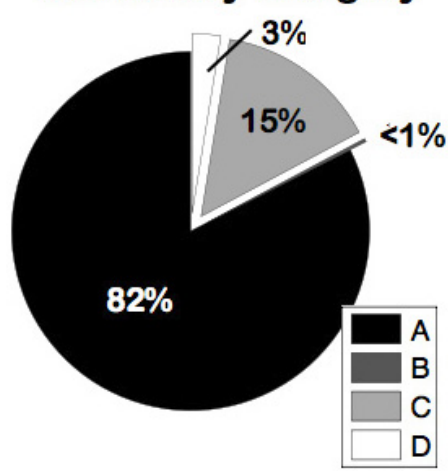

Fig. 7. Spill-over distribution between diffusive and migration processes (left diagram) and life history category (right diagram) (see Table 1). The total spill-over of the AMP was estimated to 11 tons.

the large predator group immediately increased in the MPA after fishery closure, before the increase of their potential prey biomass. Such behaviour was not included in the model, so the difference between the model predictions and field observations in large predator biomass could be due to this sanctuary effect.

The spill-over predicted by the model mainly comes from fish diffusion through the MPA boundary. This result is somewhat surprising, given very little interface between the MPA and the surrounding, non-protected environment in comparison with the MPA size (Fig. 1). However, most of this diffusion spill-over is due to local spawner species, which include species that are strongly over-estimated in biomass by the model. Furthermore, the calculation of the diffusive spill-over actually includes larval export for these species. Spawning in OSMOSE is currently represented as an even redistribution of eggs over the entire model grid, regardless of the position of the adult biomass. Hence, any increase in the biomass of the local spawners in the MPA generates an increase in the number of eggs released in the non-protected area.

The trends in biomass change of the seasonal migrating species (category C) and juvenile species (category B) were correctly represented by the model. Thus, their share in the total spill-over, $25 \%$, is more reliably estimated, even if their biomass values were generally under-estimated. However, these species migrate over quite long distances toward the open sea. Thus, this part of the spill-over is diluted in a very large area and might not be detectable for local fisheries, except at the time of fish transition at the MPA boundary.

\section{Conclusion}

The model configuration presented here, although imperfect, provides promising fish assemblage modelling results in the presence of different life histories. Four categories of life history were defined, and for 3 of them, OSMOSE was adapted to take into account parameters other than fecundity and larval mortality to determine their population dynamics. Ideally, the species groups represented should share not only ecological and trophic categories but also other characteristics such as growth parameters, range of potential prey size and allometric relationships. However, since each group was largely dominated in biomass by the type-species, we considered this approximation as acceptable.

Discrepancies between model predictions and field observations suggested that for the large predators group, the sanctuary effect might be significant, as the food availability alone did not allow the model to reproduce their increase in biomass in the MPA. It is difficult to estimate the potential effect of such a sanctuary effect that may cause the arrival of more predators in the MPA, as it may have complex implications for the whole fish assemblage through trophic cascade. However, a number of model outputs, not presented here, allow size spectra, trophic flows and spatial distributions to be checked.

Future improvements of the Bamboung configuration include the development of species habitat definitions that might play a major role in predator-prey encounters rate. This should allow the predicted trophic flows to more closely match reality by including stomach contents and expert advice. Additionally, local spawners should be differentiated between sedentary species spawning inside the MPA and other species that distribute their spawning all over the model grid, as currently is the standard in OSMOSE. The relationship between the hypotheses made about fish movements, spatial grid resolution and model time step also need to be studied in more detail for each species, as the hypotheses might have major implications for the average time spent in the MPA (Apostolaki et al. 2002; Moustakas et al. 2011) The question remains how to overcome the difficulty of accessing field information based on ecological traits that cannot be extracted from standard observation protocols. Identification of local ecological knowledge could aid in filling this gap as needed for model configuration improvement. Such an approach would also legitimatize the use of model predictions for fishery management purposes among local fishers (Johannes et al. 2000; Moreno-Báez et al. 2010).

Acknowledgements. The authors are grateful to the Diassanga research vessel crew, and particularly to Oumar Sadio for his work on data collection and for interesting discussions. Gaspard Bertrand did the initial model calibration "by hand". Phytoplankton and zooplankton data were provided by Marc Pagano, Marc Bouvy and Jacques Panfili and his team from field studies. Philippe Verley, Yune Shin and Dawit Yemane provided very valuable help on OSMOSE usage. 
We extend our gratitude to all of them. This work was done in the framework of the AMPHORE program funded by the French National Research Agency (ANR). David M. Kaplan was supported by the AMPED project (www.amped.ird.fr) through a grant from the ANR, Systerra Programme, grant number ANR-08-STRA-03.

\section{References}

Albaret J.J., Simier M., Darboe F.S., Ecoutin J.M., Raffray J., de Morais L.T., 2004, Fish diversity and distribution in the Gambia Estuary, West Africa, in relation to environmental variables. Aquat. Living Resour. 17, 35-46.

Apostolaki P., Milner-Gulland E.J., McAllister M.K., Kirkwood G.P., 2002, Modelling the effects of establishing a marine reserve for mobile fish species. Can. J. Fish. Aquat. Sci. 59, 405-415.

Ball I.R., Possingham H.P., Watts M., 2009, Marxan and relatives: software for spatial conservation prioritisation. Spatial conservation prioritisation: quantitative methods and computational tools. Oxford University Press, Oxford, pp.185-195.

Christensen V., Ferdaña Z., Steenbeek J., 2009, Spatial optimization of protected area placement incorporating ecological, social and economical criteria. Ecol. Model. 220, 2583-2593.

Christensen V., Walters C.J., Pauly D., et al., 2000, Ecopath with Ecosim: a user's guide. University of British Columbia, Fisheries Centre, Vancouver, Canada and ICLARM, Penang, Malaysia.

Claudet J., Osenberg C.W., Benedetti-Cecchi L., Domenici P., GarcíaCharton J., Pérez-Ruzafa A., Badalamenti F., Bayle-Sempere J., Brito A., Bulleri F., Culioli J., Dimech M., Falcón J.M., Guala I., Milazzo M., Sánchez-Meca J., Somerfield P.J., Stobart B., Vandeperre F., Valle C., Planes S., 2008, Marine reserves: size and age do matter. Ecol. Lett. 11, 481-489.

Claudet J., Osenberg C.W., Domenici P., Badalamenti F., Milazzo M., Falcón J.M., Bertocci I., Benedetti-Cecchi L., García-Charton J.A., Goñi R., Borg J.A., Forcada A., de Lucia G.A., Pérez-Ruzafa Á., Afonso P., Brito A., Guala I., Diréach L.L., Sanchez-Jerez P., Somerfield P.J., Planes S., 2010, Marine reserves: Fish life history and ecological traits matter. Ecol. Appl. 20, 830-839.

Colléter M., Gascuel D., Ecoutin J.M., Tito de Morais L., 2012, Modelling trophic flows in ecosystems to assess the efficiency of marine protected area (MPA), a case study on the coast of Senegal. Ecol. Model. 232, 1-13.

Denney N.H., Jennings S., Reynolds J.D., 2002, Life-history correlates of maximum population growth rates in marine fishes. Proc. R. Soc. Lond. B 269, 2229-2237.

Duboz R., Versmisse D., Travers M., Ramat E., Shin Y.J., 2010, Application of an evolutionary algorithm to the inverse parameter estimation of an individual-based model. Ecol. Model. 221, 840-849.

Ecoutin J.M., Simier M., Albaret J.J., Laë R., Tito de Morais L., 2010, Changes over a decade in fish assemblages exposed to both environmental and fishing constraints in the Sine Saloum estuary (Senegal). Estuar. Coast. Shelf Sci. 87, 284-292.

Froese R., Pauly D., 2000, FishBase 2000: concepts, design and data sources. ICLARM Contribution 1594.

Grüss A., Kaplan D.M., Guénette S., Roberts C.M., Botsford L.W., 2011, Consequences of adult and juvenile movement for marine protected areas. Biol. Conserv. 144, 692-702.
Johannes, R.E. Freeman, M.M.R. Hamilton, R.J., 2000, Ignore fishers' knowledge and miss the boat. Fish Fish. 1, 257-271.

Kaplan D.M., Planes S., Fauvelot C., Brochier T., Lett C., Bodin N., Le Loc'h F., Tremblay Y., Georges J.Y., 2010, New tools for the spatial management of living marine resources. Curr. Opinion Environ. Sustain. 2, 88-93.

Kellner J.B., Tetreault I., Gaines S.D., Nisbet R.M., 2007, Fishing the line near marine reserves in single and multispecies fisheries. Ecol. Appl. 17, 1039-1054.

McClanahan T.R., Marnane M.J., Cinner J.E., Kiene W.E., 2006, A comparison of marine protected areas and alternative approaches to coral-reef management. Curr. Biol. 16 1408-1413.

Moreno-Báez M., Orr B.J., Cudney-Bueno R., Shaw W.W., 2010, Using fishers' local knowledge to aid management at regional scales: spatial distribution of small-scale fisheries in the northern Gulf of California, Mexico. Bull. Mar. Sci. 86, 339-353.

Moustakas A., Silvert W., 2011, Spatial and temporal effects on the efficacy of marine protected areas: implications from an individual based model. Stoch. Environ. Res. Risk Assessm. 25, 403413.

Pauly D., Christensen V., Guenette S., Pitcher T.J., Sumaila U.R., Walters C.J., Watson R., Zeller D., 2002, Towards sustainability in world fisheries. Nature 418, 689-695.

Pelletier D., Claudet J., Ferraris J., Benedetti-Cecchi L., GarcìaCharton J.A., 2008, Models and indicators for assessing conservation and fisheries-related effects of marine protected areas. Can. J. Fish. Aquat. Sci. 65, 765-779.

Plagányi E.E., 2007, Models for an ecosystem approach to fisheries. Food \& Agriculture Org.

Roberts C.M., Hawkins J.P., Gell F.R., 2005, The role of marine reserves in achieving sustainable fisheries. Phil. Trans. R. Soc. B $360,123-132$.

Russ G.R., Alcala A.C., Maypa A.P., Calumpong H.P., White A.T., 2004, Marine reserve benefits local fisheries. Ecol. Appl. 14, 597-606.

Shin Y.J., Cury P., 2001a, Exploring fish community dynamics through size-dependent trophic interactions using a spatialized individual-based model. Aquat. Living Resour. 14, 65-80.

Shin Y.J., Cury P., 2001b, Simulation of the effects of marine protected areas on yield and diversity using a multispecies, spatially explicit, individual-based model. Spat. Process. Manage. Mar. Popul. 627-641.

Simier M., Blanc L., Aliaume C., Diouf P., Albaret J., 2004, Spatial and temporal structure of fish assemblages in an. Estuar. Coast. Shelf Sci. 59, 69-86.

Villanueva M.C., Laleye P., Albaret J.J., Lae R., de Morais L.T., Moreau J., 2006, Comparative analysis of trophic structure and interactions of two tropical lagoons. Ecol. Model. 197, 461-477.

White J.W., Botsford L.W., Baskett M.L., Barnett L.A., Barr R.J., Hastings A., 2011, Linking models with monitoring data for assessing performance of no-take marine reserves. Front. Ecol. Environ. 9, 390-399.

White J.W., Botsford L.W., Moffitt E.A., Fischer D.T., 2010, Decision analysis for designing marine protected areas for multiple species with uncertain fishery status. Ecol. Appl. 20, 1523-1541.

Yemane D., Shin Y.J., Field J.G., 2009, Exploring the effect of marine protected areas on the dynamics of fish communities in the southern Benguela: an individual-based modelling approach. ICES J. Mar. Sci. 66, 378-387. 